\title{
OS LIMITES DA OBRIGAÇÃO DA REPOSIÇÃO FLORESTAL E O SEU ALCANCE AOS NOVOS PROPRIETÁRIOS: INAPLICABILIDADE DA OBRIGAÇÃO IN PROPTER REM À IMÓVEIS COM SUPRESSÃO VEGETAL PREEXISTENTE
}

\author{
Lorena Saboya Vieira Soares* \\ Alessandra Anchieta Moreira Lima de Aguiar**
}

\begin{abstract}
Resumo: O estudo propõe uma reflexão acerca da impossibilidade de aplicação da obrigação in propter rem aos casos de pagamento de reposição florestal, considerada como o ato de repor uma floresta consumida na proporção indicada por lei, cobrada a novo proprietário de imóvel que não executou a supressão vegetal autorizada pelo órgão ambiental competente. Discute-se que o pagamento de reposição florestal deve ser feito no momento da aquisição da autorização da supressão vegetal ou na vigência da mesma, ficando, assim, prejudicados os casos de cobrança após esse período, pois fere o próprio princípio da legalidade, norteador dos atos da Administração Pública.
\end{abstract}

Palavras-Chave: Obrigação. Reposição Florestal. Novo Proprietário. Impossibilidade de pagamento. Princípio da Legalidade.

\section{THE LIMITS OF THE FOREST ORBIGATION REPLACEMENT AND ITS RANGE TO NEW OWNERS: THE INABILABILITY OF THE IN PROPTER REM OBLIGATION TO PROPERTIES WITH PRE-EXISTING VEGETABLE SUPPRESSION}

\begin{abstract}
The study proposes a reflection about the in propter rem obligation impossibility applying in cases of forest replenishment payment, considered as the act of restoring a forest consumed in the proportion indicated by law, charged to a new property owner that did not execute the plant suppression authorized by the competent environmental agency. It is argued that the forest replenishment payment must be made at the time of the suppression authorization acquisition or, during its validity, never after this period, since it violates the legality principle that guides the acts of the Public Administration.
\end{abstract}

\footnotetext{
* Doutoranda em Políticas Públicas pela Universidade Federal do Maranhão - UFMA. Mestre em Saúde e Ambiente pela Universidade Federal do Maranhão - UFMA. Membro da Comissão de Meio Ambiente da OAB/MA. Advogada. Sócia-proprietária do escritório Correa \& Saboia Advogados. Professora de Direito Ambiental da Graduação e Pós Graduação da Universidade CEUMA. E-mail: lorenasaboia@gmail.com.

** Mestranda em Meio Ambiente pela Universidade Ceuma. Membro do Colegiado do Curso de Direito e do Conselho de Ensino, Pesquisa e Extensão da Universidade Ceuma. Advogada do escritório Aguiar Advogados Associados. Professora de Direito Administrativo e Empresarial da Graduação da Universidade CEUMA. E-mail: alessandramoreiraadv@hotmail.com
}

Rev. de Direito Ambiental e Socioambientalismo | e-ISSN: 2525-9628 | Maranhão | v. 3 | n. 2 | p. 173 - 187 | Jul/Dez. 2017 
Keywords: Obligation. Forest replenishment. New owner. Impossibility of payment. Principle of legality.

\section{INTRODUÇÃO}

A problemática do desmatamento no Brasil sempre foi um grande desafio para as gestões ambientais. Diversas tentativas e programas de enfrentamento ao desmatamento já foram realizadas sem conseguir solucionar a problemática de uma vez por todas.

O desmatamento na Amazônia Legal cresceu bastante nos últimos 5 anos, e, apenas neste ultimo, houve uma tímida melhora. Segundo dados do Instituto do Homem e Meio Ambiente da Amazônia, entre agosto de 2016 a julho de 2017, mesmo com declínio no percentual comparado ao ano anterior, ainda foi desmatada uma área nativa de $2.834 \mathrm{~km}^{2}$, que corresponde a quase ao dobro do território da cidade de São Paulo ${ }^{1}$ (IMAZON, 2017).

Alguns aspectos podem justificar o cenário atual, mas, um deles, é a própria dependência brasileira do uso da lenha para atividades econômicas, como para o mercado energético.

Segundo dados do Ministério de Minas e Energia (BRASIL, 2007) em 1970, a lenha era o principal recurso energético do país, representando 45,6\% do consumo final de energia.

A produção de lenha em 2013 foi de 79.290 mil toneladas, distribuída da seguinte forma: 1,4\% da produção foi utilizada para geração de energia elétrica, 32,8\% foi transformada em carvão vegetal e $65,8 \%$ destinou-se ao consumo final energético. Do que foi destinado ao consumo final, $47,6 \%$ foi consumido pelas indústrias, 35,5\% pelas residências, $16,3 \%$ pelo setor agropecuário e $0,6 \%$ pelo setor comercial. (EMPRESA DE PESQUISA ENERGÉTICA, 2014).

A produção de carvão vegetal no Brasil em 2013 atingiu 6.615 mil toneladas, com consumo de $72,6 \%$ pela indústria de ferro-gusa e aço (EMPRESA DE PESQUISA ENERGÉTICA, 2014). Já em 2015, houve um decréscimo nessa produção, caindo para 797,0 mil toneladas. (IBGE, 2015)

Entretanto, apesar dos altos rendimentos, a produção de carvão vegetal e as demais atividades que necessitam da matéria-prima vegetal, bem como o agronegócio ou a monocultura, necessitam substituir ou usar a vegetação nativa. De acordo com dados da

\footnotetext{
${ }^{1}$ A capital paulista tem área de $1.521 \mathrm{~km}^{2}$.
}

Rev. de Direito Ambiental e Socioambientalismo | e-ISSN: 2525-9628 | Maranhão | v. 3 | n. 2 | p. 173 - 187 | Jul/Dez. 2017 


\section{OS LIMITES DA OBRIGAÇÃO DA REPOSIÇÃO FLORESTAL E O SEU ALCANCE AOS NOVOS PROPRIETÁRIOS: INAPLICABILIDADE DA OBRIGAÇÃO IN PROPTER REM À IMÓVEIS COM

Associação Mineira de Silvicultura (2009), as plantações florestais não são capazes de suprir toda a demanda das empresas, havendo um deficit anual médio de quase 50\% (no mínimo 100 mil ha), suprido com resíduos e manejo de florestas naturais. (SIMIONI, et al, 2017).

Significa dizer que, as florestas nativas brasileiras são as grandes sacrificadas neste processo produtivo, e, o pior, são insuficientes para o atendimento total da demanda. Sem falar da pressão diferenciada em termos de região do Brasil.

Os principais Estados produtores de carvão vegetal em 2015 foram o Maranhão (229,3mil toneladas), Piaú́ (154,9 mil toneladas), Bahia (103,0mil toneladas), Mato Grosso do Sul (100,1mil toneladas) e Tocantins (70,2mil toneladas). As maiores produções municipais foram em Grajaú (MA), Jerumenha (PI), Baianópolis (BA) e Regeneração (PI). (IBGE, 2015)

Diante dessa realidade, uma das estratégias compensatórias criadas pelo legislador, foi a instituição de um mecanismo que devolvesse ao meio aquilo que fosse retirado da natureza, como forma de "contrabalançar" a retirada da floresta.

A partir desse intuito, surge no Brasil a figura da Reposição Florestal, instrumento obrigacional relacionado aos casos de supressão de vegetação nativa ou uso de matéria-prima oriunda dessas supressões.

O termo reposição florestal é, assim, o ato de repor uma floresta consumida, na proporção indicada por lei.

A exigência da Reposição Florestal, hoje regulamentada pelo Código Florestal (lei 12.651/12), dá-se a partir da geração de uma obrigação, vinculada a um direito, ou seja, o direito de suprimir a vegetação está atrelado à obrigação de repor a floresta.

Os questionamentos acerca da aplicação obrigacional da Reposição Florestal já foram tema de diversos embates jurídicos, visto a sua tamanha repercussão em questões relacionadas, principalmente, com aquisições de propriedades com passivos ambientais de reposição florestal.

Não se trata de discutir a natureza da transmissão obrigacional com relação aos danos ambientais causados por antigos proprietários, pois, sabe-se da superada discussão em virtude do entendimento de que o novo proprietário assume as condições em que se encontra o imóvel, independentemente da autoria do dano, o que configura, inclusive, a responsabilidade ambiental civil objetiva.

Rev. de Direito Ambiental e Socioambientalismo | e-ISSN: 2525-9628 | Maranhão | v. 3 | n. 2 | p. 173 - 187 | Jul/Dez. 2017 
O que se pretende é uma aprofundada discussão acerca do instituto da reposição florestal, que possui natureza compensatória decorrente de supressões vegetais autorizadas pelos órgãos ambientais competentes.

O estudo busca, primeiramente, compreender o tratamento dado pelo novo Código Florestal ao instituto da reposição florestal, e, em seguida, refletir sobre a comprovação da reposição florestal, suas condições e requisitos, para, ao fim, estabelecer o nexo acerca dos limites da cobrança da reposição florestal e o seu alcance aos novos proprietários.

\section{A REPOSiÇÃo FlORESTAl E SUA REgUlamentaÇÃo PELO Código FLORESTAL}

Segundo Braga apud Sabbag (2011), a primeira manifestação legislativa que demonstra a preocupação com o uso das florestas data de 1906, quando foi incluído um apêndice focado na conservação. O Instituto Nacional do Pinho, em 1941, foi onde primeiro surgiu a proposta de reposição da floresta de rendimento em proporções determinadas com a mesma espécie abatida. $\mathrm{O}$ instituto figurava como órgão apto a realizar a reposição por meio do recolhimento de um valor correspondente a realizar programas de cooperação com proprietários (fomento florestal).

No entanto, foi somente em 1965, com o Código Florestal (Lei 4.771/65) que a reposição florestal é melhor regulamentada, apesar da redação final ter sido feita em 2006, pela Lei $n^{\circ} 11.284$.

O artigo 19 do antigo Código Florestal estabelecia:

Art. 19. A exploração de florestas e formações sucessoras, tanto de domínio público como de domínio privado, dependerá de prévia aprovação pelo órgão estadual competente do Sistema Nacional do Meio Ambiente - SISNAMA, bem como da adoção de técnicas de condução, exploração, reposição florestal e manejo compatíveis com os variados ecossistemas que a cobertura arbórea forme.

$\S 1^{\circ}$ Compete ao Ibama a aprovação de que trata o caput deste artigo:

I - nas florestas públicas de domínio da União;

II - nas unidades de conservação criadas pela União;

III - nos empreendimentos potencialmente causadores de impacto ambiental nacional ou regional, definidos em resolução do Conselho Nacional do Meio Ambiente - CONAMA.

$\S 2^{\circ}$ Compete ao órgão ambiental municipal a aprovação de que trata o caput deste artigo:

I - nas florestas públicas de domínio do Município;

Rev. de Direito Ambiental e Socioambientalismo | e-ISSN: 2525-9628 | Maranhão | v. 3 | n. 2 | p. 173 - 187 | Jul/Dez. 2017 
II - nas unidades de conservação criadas pelo Município;

III - nos casos que lhe forem delegados por convênio ou outro instrumento admissível, ouvidos, quando couber, os órgãos competentes da União, dos Estados e do Distrito Federal.

$\S 3^{\text {o }}$ No caso de reposição florestal, deverão ser priorizados projetos que contemplem a utilização de espécies nativas.

A regra para cumprimento da reposição florestal obedecia aos critérios estabelecidos nos artigos 20 e 21 do Código de 1965 :

\begin{abstract}
Art. 20. As empresas industriais que, por sua natureza, consumirem grande quantidades de matéria prima florestal serão obrigadas a manter, dentro de um raio em que a exploração e o transporte sejam julgados econômicos, um serviço organizado, que assegure o plantio de novas áreas, em terras próprias ou pertencentes a terceiros, cuja produção sob exploração racional, seja equivalente ao consumido para o seu abastecimento.

Parágrafo único. O não cumprimento do disposto neste artigo, além das penalidades previstas neste Código, obriga os infratores ao pagamento de uma multa equivalente a $10 \%$ (dez por cento) do valor comercial da matéria-prima florestal nativa consumida além da produção da qual participe.

Art. 21. As empresas siderúrgicas, de transporte e outras, à base de carvão vegetal, lenha ou outra matéria prima florestal, são obrigadas a manter florestas próprias para exploração racional ou a formar, diretamente ou por intermédio de empreendimentos dos quais participem, florestas destinadas ao seu suprimento.

Parágrafo único. A autoridade competente fixará para cada empresa o prazo que lhe é facultado para atender ao disposto neste artigo, dentro dos limites de 5 a 10 anos.
\end{abstract}

O novo Código Florestal, manteve a regra do antigo quanto a exigência da reposição

florestal, com algumas pequenas modificações, resumidas em seu artigo 33:

Art. 33. As pessoas físicas ou jurídicas que utilizam matéria-prima florestal em suas atividades devem suprir-se de recursos oriundos de:

I - florestas plantadas;

II - PMFS de floresta nativa aprovado pelo órgão competente do Sisnama;

III - supressão de vegetação nativa autorizada pelo órgão competente do Sisnama;

IV - outras formas de biomassa florestal definidas pelo órgão competente do Sisnama.

$\S 1^{\circ}$ São obrigadas à reposição florestal as pessoas físicas ou jurídicas que utilizam matéria-prima florestal oriunda de supressão de vegetação nativa ou que detenham autorização para supressão de vegetação nativa.

$\S 2$ o É isento da obrigatoriedade da reposição florestal aquele que utilize:

I - costaneiras, aparas, cavacos ou outros resíduos provenientes da atividade industrial

II - matéria-prima florestal:

a) oriunda de PMFS;

Rev. de Direito Ambiental e Socioambientalismo | e-ISSN: 2525-9628 | Maranhão | v. 3 | n. 2 | p. 173 - 187 | Jul/Dez. 2017 
b) oriunda de floresta plantada;

c) não madeireira.

§ 3o A isenção da obrigatoriedade da reposição florestal não desobriga o interessado da comprovação perante a autoridade competente da origem do recurso florestal utilizado.

§ 4을 A reposição florestal será efetivada no Estado de origem da matériaprima utilizada, mediante o plantio de espécies preferencialmente nativas, conforme determinações do órgão competente do Sisnama.

Basicamente, a modificação do atual Código concentrou-se em recepcionar a regra de competência dos órgãos ambientais definidas na Lei Complementar 140/11, e, por isso, não estabeleceu as matérias que competem a cada órgão no que se refere à reposição florestal, deixando claro, ainda, que a reposição será efetivada no Estado de origem na matéria-prima.

A nova Lei cria, ainda, a possibilidade de isenção da reposição florestal, como os casos de utilização de costaneiras, aparas, cavacos ou outros resíduos provenientes da atividade industrial, matéria-prima florestal oriunda de PMFS, oriunda de floresta plantada ou não madeireira.

A forma de cumprimento da reposição florestal, no Estado do Maranhão, dá-se pela apresentação de créditos florestais:

Artigo 44 da Portaria SEMA 13/13. aquele que utiliza matéria-prima florestal
oriunda de supressão de vegetação natural cumprirá a reposição florestal por
meio da apresentação de créditos de reposição florestal equivalentes ao
volume de matéria-prima florestal a ser utilizado.

Discute-se, se o cumprimento de reposição florestal a partir de créditos florestais, como é o caso do Estado do Maranhão, não entraria em confronto com o novo Código Florestal que exige, claramente, que a reposição florestal seja efetuada mediante o plantio de espécies preferencialmente nativas.

Verifica-se, assim, que a forma de cobrança da reposição florestal pode variar de Estado para Estado, por se tratar de competência supletiva, embora os limites devam ser observados, bem como as regras atinentes à norma geral, que é o próprio Código Florestal, o qual prevalece em caso de confronto com normas estaduais ou municipais.

Um dos limites observados pela Lei é a própria exigência de plantio de espécies nativas. Outra é a isenção prevista no novo Código. 
Assim, apesar dos Estados serem dotados de competência para exigir o cumprimento da reposição florestal, e inclusive, legislar sobre a matéria, necessita, obrigatoriamente, obedecer ao que for estabelecido no Código Florestal.

\section{A INAPLICABILIDADE DA OBRIGAÇÃO IN PROPTER REM RELATIVA AO PAGAMENTO DE REPOSIÇÃO FLORESTAL POR NOVO PROPRIETÁRIO DE ÁREA COM SUPRESSÃO VEGETAL PREEXISTENTE}

Antes de adentar nos aspectos específicos trazidos pelo Código Florestal no que concerne ao pagamento da reposição florestal, insta trazer a baila o conceito de obrigação in propter rem e sua aplicabilidade.

Segundo o Segundo o art. 225, § 3o, da Constituição Federal de 1988, as condutas e atividades consideradas lesivas ao meio ambiente sujeitarão os infratores, pessoas físicas ou jurídicas, a sanções penais e administrativas, independentemente da obrigação de reparar os danos causados.

O famoso e discutido parágrafo terceiro do artigo 225 da Carta Magna parece estabelecer que toda e qualquer reparação de danos ambientais não se sujeita a prazo prescricional.

Longe de discutir o conceito e a legalidade do dano ambiental, se foi ou não passível de licenciamento, já que não é o objeto deste estudo, importante relembrar a regra constitucional para a reflexão que se propõe nesse trabalho.

O instituto da responsabilidade ambiental objetiva, que, no âmbito cível exige, do responsável pela conduta (ação ou omissão), a reparação pela alteração adversa das características do ambiente (art. $3^{\circ}$ da Lei Federal no 6.938/1981), em tese, não pode ser aplicada aos casos de reposição florestal, pelo menos no que diz respeito a sua imprescritibilidade.

Art. $3^{\circ}$ - Para os fins previstos nesta Lei, entende-se por:

I - meio ambiente, o conjunto de condições, leis, influências e interações de ordem física, química e biológica, que permite, abriga e rege a vida em todas as suas formas;

II - degradação da qualidade ambiental, a alteração adversa das características do meio ambiente;

III - poluição, a degradação da qualidade ambiental resultante de atividades que direta ou indiretamente:

Rev. de Direito Ambiental e Socioambientalismo | e-ISSN: 2525-9628 | Maranhão | v. 3 | n. 2 | p. 173 - 187 | Jul/Dez. 2017 
a) prejudiquem a saúde, a segurança e o bem-estar da população;

b) criem condições adversas às atividades sociais e econômicas;

c) afetem desfavoravelmente a biota;

d) afetem as condições estéticas ou sanitárias do meio ambiente;

e) lancem matérias ou energia em desacordo com os padrões ambientais estabelecidos;

IV - poluidor, a pessoa física ou jurídica, de direito público ou privado, responsável, direta ou indiretamente, por atividade causadora de degradação ambiental;

V - recursos ambientais: a atmosfera, as águas interiores, superficiais e subterrâneas, os estuários, o mar territorial, o solo, o subsolo, os elementos da biosfera, a fauna e a flora.

Isto porque, não se pode confundir dano com reposição florestal. A reposição florestal, como será mais aprofundado adiante, independe da licitude ou ilicitude da conduta, visto que é resultado da exploração, utilização, transformação e consumo de produto florestal, salvo as exceções expressamente previstas.

Diferentemente é o tratamento dado ao dano ambiental que, de regra, é resultado de uma conduta infracional, e, de logo, faz nascer a responsabilidade civil ambiental objetiva, fincada na teoria do risco integral, e consubstanciada na obrigação in propter rem.

E, mesmo que não seja resultado de conduta ilícita, como é do entendimento da maioria dos doutrinadores, o dano, se resultar em "degradação" in pejus ao meio ambiente, desencadeia a imposição obrigatória de reparação, independentemente da culpa, conforme o que dispõe o do artigo $\S 1^{\circ}$ do 14 da Lei 6.938/81:

$\S 1^{\circ}$. Sem obstar a aplicação das penalidades previstas neste artigo, é o poluidor obrigado, independentemente da existência de culpa, a indenizar ou reparar os danos causados ao meio ambiente e a terceiros, afetados por sua atividade. O Ministério Público da União e dos Estados terá legitimidade para propor ação de responsabilidade civil e criminal, por danos causados ao meio ambiente.

Segundo Pablo Stolze Gagliano e Rodolfo Pamplona Filho (2016), existem obrigações, em sentido estrito, que decorrem de um direito real sobre determinada coisa, aderindo a essa e, por isso, acompanhando-a nas modificações do seu titular. São as chamadas obrigações in rem, ob rem ou propter rem, também conhecidas como obrigações reais ou mistas.

Neste sentido, prevalece a regra de que a obrigação de reparar danos ambientais é dever do proprietário de um imóvel, seja ele autor ou não do dano ambiental.

Rev. de Direito Ambiental e Socioambientalismo | e-ISSN: 2525-9628 | Maranhão | v. 3 | n. 2 | p. 173 - 187 | Jul/Dez. 2017 


\section{OS LIMITES DA OBRIGAÇÃO DA REPOSIÇÃO FLORESTAL E O SEU ALCANCE AOS NOVOS PROPRIETÁRIOS: INAPLICABILIDADE DA OBRIGAÇÃO IN PROPTER REM À IMÓVEIS COM SUPRESSÃO VEGETAL PREEXISTENTE}

Como já dito, a reposição florestal não significa o mesmo que dano ambiental, e, por isso, não pode obedecer a mesma regra a este estipulada.

Até porque, se os dois institutos tivessem o mesmo significado e natureza jurídica, estaríamos diante de uma clara ocorrência do bis in idem, assim considerado o fenômeno que consiste na repetição (bis) de uma sanção sobre mesmo fato (in idem) proibido no direito brasileiro. No caso, a conduta danosa ao meio ambiente.

Portanto, não se pode considerar os dois institutos, reposição florestal e dano ambiental, como sinônimos.

O Código Florestal, em seu artigo 26, § 4ºำ deixa claro que o cumprimento da reposição florestal ocorre no momento do requerimento da autorização para a supressão vegetal, ou seja, quando o interessado em suprimir a vegetação da propriedade protocola seu pedido no órgão ambiental competente. Neste instante, já há a necessidade de informar a reposição ou compensação florestal:

\footnotetext{
Art. 26, § 4‥ A supressão de vegetação nativa para uso alternativo do solo, tanto de domínio público como de domínio privado, dependerá do cadastramento do imóvel no CAR, de que trata o art. 29, e de prévia autorização do órgão estadual competente do SISNAMA.

$\S 4^{\circ}$ O requerimento de autorização de supressão de que trata o caput conterá, no mínimo, as seguintes informações:

I - a localização do imóvel, das Áreas de Preservação Permanente, da Reserva Legal e das áreas de uso restrito, por coordenada geográfica, com pelo menos um ponto de amarração do perímetro do imóvel;

II - a reposição ou compensação florestal, nos termos do $\S 4^{\circ}$ do art. 33;

III - a utilização efetiva e sustentável das áreas já convertidas;

IV - o uso alternativo da área a ser desmatada.
}

Percebe-se que a reposição constitui condição sine qua non para que o órgão ambiental inicie a avaliação do pedido de supressão vegetal protocolado, sem o que não há possibilidade sequer de análise do mesmo.

Mais a frente, no artigo 33, $\S 1^{\circ}$, o Código Florestal preceitua que o Requerente (pessoa física ou jurídica) deve realizar a reposição florestal quando de posse da autorização para supressão de vegetação nativa:

Artigo 33, $\S 1^{\circ}$. São obrigadas à reposição florestal as pessoas físicas ou jurídicas que utilizam matéria-prima florestal oriunda de supressão de vegetação nativa ou que detenham autorização para supressão de vegetação nativa.

Rev. de Direito Ambiental e Socioambientalismo | e-ISSN: 2525-9628 | Maranhão | v. 3 | n. 2 | p. 173 - 187 | Jul/Dez. 2017 
Importante destacar que o legislador reduziu a obrigação de reposição florestal a dois casos específicos: 1) àqueles que utilizem matéria-prima florestal oriunda de supressão vegetal nativa; e 2) àqueles que detenham autorização para supressão vegetal nativa.

Tratam-se de situações completamente distintas, visto que, no primeiro caso haverá uso de matéria-prima oriunda de exploração da vegetação, como, por exemplo, uso para fabricação de carvão, enquanto que na segunda hipótese legal, não há uso da matéria-prima, mas simples aquisição de autorização para supressão vegetal nativa.

Em ambas as situações resta claro que a reposição florestal está atrelada à vegetação nativa, seja contemplando o uso da matéria-prima, seja para simples uso da área.

A autorização para supressão vegetal compreende como o resultado de uma das atividades inerentes ao poder de polícia ou poder-dever de todos os entes federativos de proteger o meio ambiente, conforme o que estabelece o artigo 23, VI da Constituição Federal de 1988, cumprindo-lhes realizar a subsunção legal para decidir em cada caso se a intervenção atende aos comandos e às hipóteses permissivas trazidas pelo legislador.

Nesta senda, a autorização para supressão vegetal é ato precário, compreendida, segundo Carvalho Filho (2017), como "o ato administrativo pelo qual a Administração consente que o particular exerça atividade ou utilize bem público no seu próprio interesse. É ato discricionário e precário, com características, portanto, idênticas às da permissão.

Assim, uma vez emitida a autorização, a sua validade fica condicionada à data declarada no documento oficial ou ao cumprimento do seu objeto, que é a realização da supressão da vegetação nativa, sendo que, de acordo com o que determina o Código Florestal, se o protocolo do pedido de autorização de supressão depende da comprovação da reposição florestal, significa dizer que quando a autorização é emitida a reposição florestal já fora informada pelo Requerente.

Resta preclusa, neste contexto, a possibilidade de cobrança pelo órgão ambiental ao novo proprietário da reposição florestal de áreas que já receberam suas autorizações para supressão vegetal com os devidos objetos cumpridos, quais sejam, o desmatamento das áreas, seja ou não com aproveitamento de material lenhoso.

Frisando-se que para a devida cobrança, além de ser no momento da autorização para supressão, a vegetação deve, obrigatoriamente, ser nativa.

$\mathrm{Na}$ legislação ambiental do Estado do Maranhão, a exigência da reposição florestal também ocorre no ato da solicitação da supressão. 


\section{OS LIMITES DA OBRIGAÇÃO DA REPOSIÇÃO FLORESTAL E O SEU ALCANCE AOS NOVOS PROPRIETÁRIOS: INAPLICABILIDADE DA OBRIGAÇÃO IN PROPTER REM À IMÓVEIS COM \\ SUPRESSÃO VEGETAL PREEXISTENTE}

É o que estabelece a Portaria SEMA n ${ }^{\mathrm{o}} 13 / 2013$, em seu art. 32, § $2^{\circ}$ :

A solicitação de Supressão de Vegetação de imóveis rurais não classificados como pequena propriedade ou posse rural familiar conterá, no mínimo, as seguintes informações:

I - A localização do imóvel, das Áreas de Preservação Permanente - APPs da Reserva Legal e das áreas de uso restrito, por coordenada geográfica, com pelo menos um ponto de amarração do perímetro do imóvel;

II - A reposição ou compensação florestal;

III - A utilização efetiva e sustentável das áreas já convertidas;

IV - O uso alternativo da área a ser desmatada;

V - A volumetria solicitada (se for o caso).

A mesma Portaria acompanha ao já exigido pelo Código Florestal quanto à obrigação do utilizador da matéria-prima ou detentor da Autorização de Supressão a de realizar a reposição florestal:

Art. 43. De acordo com a legislação vigente, é obrigada à reposição florestal a pessoa física ou jurídica que:

I - utiliza matéria-prima florestal oriunda de supressão de vegetação natural; II - detenha a Autorização de Supressão de Vegetação Natural.

A norma Estadual diferencia-se da Federal, no que se refere à regra da reposição florestal, quanto à tipologia da vegetação: a primeira utiliza a terminologia "natural", enquanto que a segunda utiliza a "nativa".

Importante ressaltar que Segundo o relatório da FAO (Food and Agriculture Organization of the United Nations), entre 2010 e 2015, cerca de 6,5 milhões de hectares de florestas nativas foram perdidos no mundo, sendo o Brasil foi o país que apresentou a maior taxa de perda de mata nativa.

Independentemente de se tratar de vegetação nativa ou natural, a regra para a exigência da reposição florestal não muda: deve ser comprovada no ato do pedido de supressão e é obrigatória aos casos de uso de matéria-prima oriunda de exploração florestal.

A excepcionalidade da aplicação do instituto da obrigação propter rem reside exatamente no fato do momento em que nasce e se encerra a obrigação, qual seja, na validade da autorização da supressão.

Rev. de Direito Ambiental e Socioambientalismo | e-ISSN: 2525-9628 | Maranhão | v. 3 | n. 2 | p. 173 - 187 | Jul/Dez. 2017 
Significa dizer que uma autorização para supressão vegetal emitida e seu objeto cumprido pelo detentor da mesma, prescreve a possibilidade do órgão ambiental competente cobrar pela reposição florestal.

Esta regra fica ainda mais clara quando se analisa o disposto no $\S 2^{\circ}$ da Portaria SEMA n $13 / 2013$, já citada acima, quando a mesma cria a possibilidade de desoneração de reposição florestal àquele detentor de autorização que não utilizou a matéria-prima:

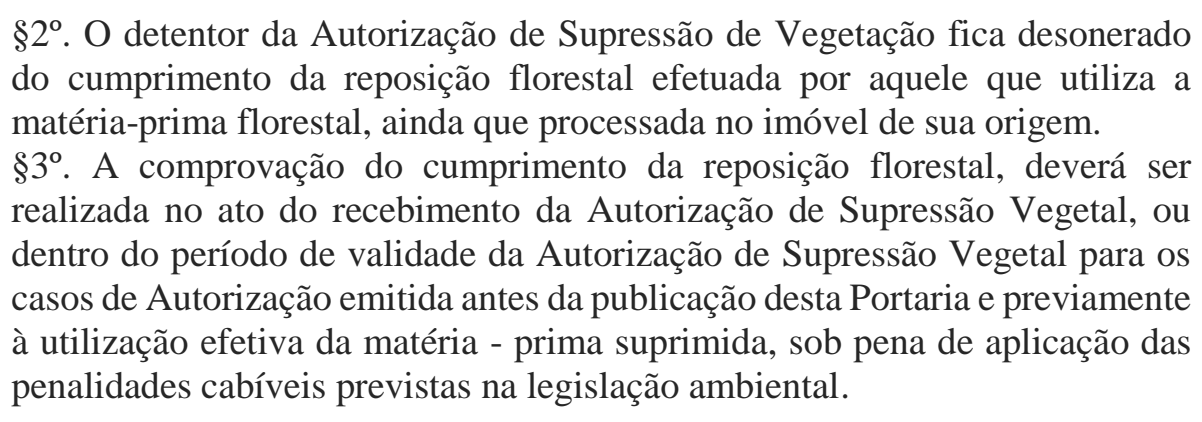

Resta claro que, se o novo proprietário, que porventura não utilizou matéria-prima oriunda da supressão vegetal autorizada pelo órgão ambiental competente e não era o detentor da autorização à época, ou seja, não recebeu a autorização, nem mesmo no período de sua validade, não possui obrigação de pagar a reposição florestal não cumprida pelo antigo proprietário.

A questão reside no fato do momento da cobrança que deve ser realizada pelo órgão ambiental competente, que, como já dito, deve ser no ato do recebimento da autorização para supressão vegetal.

Se o órgão ambiental, por sua conta exclusiva, perde o momento da cobrança, não pode fazê-la depois em respeito ao princípio da legalidade esculpido nas normas que regulamentam a matéria, o que afasta, também, o instituto da obrigação in propter rem.

O uso da matéria-prima é comprovado, no caso do Estado do Maranhão e pelo Instituto Brasileiro de Recursos Naturais Renováveis - IBAMA, através do Documento de Origem Florestal - DOF, o qual condiciona sua emissão à obrigação da reposição florestal.

Assim, presume-se que aquele que movimenta o sistema DOF, com transações relativas a matérias-primas oriundas de autorizações de vegetação (volume lenhoso), já comprovou a reposição florestal ou pelo menos deveria fazê-la.

Cabe, assim, exclusivamente, ao órgão ambiental este controle, inclusive do volume a ser reposto através do sistema DOF.

Rev. de Direito Ambiental e Socioambientalismo | e-ISSN: 2525-9628 | Maranhão | v. 3 | n. 2 | p. 173 - 187 | Jul/Dez. 2017 
A Instrução Normativa do IBAMA n 112/2006, que instituiu a obrigatoriedade do uso do Documento de Origem Florestal - DOF, em seu artigo $3^{\circ}, \S 7^{\circ}$, estabelece que o DOF somente será emitido pela pessoa física ou jurídica, quando esta estiver em situação regular com relação à obrigação da reposição florestal, nas hipóteses em que esta for exigível. A mesma exigência consta no artigo 35, §5º , da Instrução Normativa do IBAMA nº 21/2014.

O que se que deixar claro é que, se um indivíduo protocola um pedido de supressão vegetal, este pedido é apreciado e aprovado pelo órgão ambiental competente, com o devido controle do uso do material lenhoso pelo sistema DOF, e, havendo transmissão dessa propriedade a um terceiro, que não obteve benefícios da transação (venda) ou da própria supressão vegetal, não pode ser exigido dele o cumprimento da reposição florestal, porque há um momento legal pra isso, estipulado por lei.

Se o momento passa e há omissão clara do órgão competente, entende-se que se está diante da ocorrência da prescrição administrativa de exigir a reposição florestal. A Administração Pública possui prazos e momentos claros de cobrança, não podendo fazê-la a qualquer tempo, e, assim, não há que se falar em obrigação in propter rem.

\section{CONSIDERAÇÕES FINAIS}

O estudo sob comento fez considerações acerca da reposição florestal, como um importante instrumento de controle do desmatamento no Brasil, bem como de equilíbrio ambiental frente as diversas atividades econômicas que utilizam matéria-prima vegetal ou necessitam suprimir a floresta para plantio.

A reposição florestal foi regulamentada no Brasil desde o Código Florestal de 1965 e mantida no novo Código, com novos limites e regras.

As principais mudanças observados no novo Código não foram quanto à sua obrigatoriedade, mas sim, quanto à forma de cobrança que, além de necessitar, obrigatoriamente, ser resultado de uma autorização para supressão vegetal, deve ser exigida por órgão ambiental competente no prazo legal, qual seja: no momento do protocolo do pedido da autorização para supressão, ou durante a validade da mesma.

Diferenciou-se a reposição florestal do próprio dano ambiental, este sendo resultado de conduta ilícita e in pejus ao meio ambiente.

Rev. de Direito Ambiental e Socioambientalismo | e-ISSN: 2525-9628 | Maranhão | v. 3 | n. 2 | p. 173 - 187 | Jul/Dez. 2017 
A reposição florestal independe da licitude ou ilicitude da exploração, utilização, transformação e consumo de produto florestal, visto que, é resultado natural do processo de uso vegetal, excetuados os casos estipulados em lei.

Como há prazo de cobrança, bem como órgão competente para exigi-la, por se tratar de competência concorrente, o princípio da legalidade deve ser observado, ou seja, não se pode cobrar a reposição florestal fora do prazo estipulado com a justificativa de imprescritibilidade do dano ambiental, pois não se confundem.

Se há prescrição, impossível aplicação da obrigação in proter rem, posto que não há possibilidade de se transmitir aquilo que não pode mais ser cobrado.

Portanto, resta claro que, nos casos de ocorrência de autorizações para supressão vegetal cumpridas e gozadas por proprietários anteriores e devedores de reposição florestal, não há como estender-se a obrigação ao novo proprietário, ocorrendo, assim, a prescrição administrativa.

\section{REFERÊNCIAS}

BRASIL, Ministério de Minas e Energia - MME. 2007. Disponível em <http://www.mme.gov.br.htp>.

BRAGA, Lucas Palma Perez. O Papel da Reposição Florestal para a Cadeia de Bioenergia: um estudo de caso para estimativa de carbono em Piracicaba - SP. Dissertação de Mestrado apresentada à Escola Superior de Agricultura "Luiz de Queiroz" da Universidade de São Paulo. Piracicaba, 2011.

CARVALHO FILHO, José dos Santos. Manual de Direito Administrativo - 31ª Ed. 2017.

EPE, EMPRESA DE PESQUISA ENERGÉTICA. Relatório Final do Balanço Energético $\begin{array}{lllll}\text { Nacional } & - & \text { BEN } & 2014 . & \text { Disponível }\end{array}$ <http://www.epe.gov.br/Estudos/Paginas/Balanço\%20Energético\%20Nacional\%20\%20BEN/EPEdisponibilizaoRelatórioFinaldoBalançoEnergéticoNacionalBEN2014.aspx.htp>. Acesso AGO 17.

FAO, Food and Agriculture Organization of the United Nations. Disponível em <http://www.fao.org/home/en/.htm>. Acesso AGO 17.

IMAZON, INSTITUTO BRASILEIRO DO HOMEM E MEIO AMBIENTE DA AMAZÔNIA. Boletim do Desmatamento da Amazônia Legal 2017. Disponível em <http://imazon.org.br.htp>. Acesso AGO 17. 
IBGE, Instituto Brasileiro de Geografia e Estatística. Produção da Extração Vegetal e da Silvicultura 2015.

Disponível

em

<https://sidra.ibge.gov.br/pesquisa/pevs/quadros/brasil/2015.htp>. Acesso JUL 17.

PAMPLONA FILHO, Rodolfo; GAGLIANO, Pablo Stolze. Novo Curso de Direito Civil Parte Geral - Vol. 1 - $18^{\text {a }}$ Ed. 2016

SIMIONI, José Flávio et al. Evolução e concentração da produção de lenha e carvão vegetal da silvicultura no Brasil. Ciência Florestal, Santa Maria, v. 27, n. 2, p. 731-742, abr.-jun., 2017. 